Administrative Issues Journal: Connecting Education, Practice, and Research, Summer 2020,

Vol. 10, No. 1: 16 - 29. DOI: 10.5929/2020.10.1.2

\title{
A DEDUCTIVE, PARTICIPATIVE, AND ITERATIVE PROCESS: A CASE STUDY IN CURRICULAR REVIEW
}

\author{
Dr. Elizabeth Rozell, Ph.D. \\ Missouri State University \\ Dr. Jenifer Roberts, Ph.D. \\ North Central University in Arizona \\ Dr. Cathy Starr, Ph.D.
}

Oklahoma State University

Ms. Sandy Bailey, MS

\section{Baker University}

\begin{abstract}
This paper focuses on a deductive, participative, and iterative process for curricular revision at a public Midwestern university in the Merchandising and Fashion Design program. A systematic, nonlinear, organized process is presented and details specific components used in curricular review. The guiding framework for the redesign was that of Garner and Buckley (1988). That is, feedback was solicited and incorporated from educators, students, and employers. In each of the two-year process, the program was viewed as a whole, with input from faculty at every step, and also viewed from a micro-perspective by examining each course individually. The process included peer review, with each faculty member encouraged to review not only their own courses, but those of their colleagues as well. At times, the curricular review process seemed overwhelming with the significant amount of data and resource constraints to consider. The systematic process presented assisted in managing multiple considerations and constituents involved in the curriculum review. Besides maintaining a relevant and current curriculum, the process provided a multitude of benefits for the department. Significant changes were made to the curriculum, but more honest relationships were reestablished and an increased understanding among colleagues was an unexpected benefit of the lengthy, but necessary, examination of the program and resulting curricular changes in the department.
\end{abstract}

Keywords: curricular review participative deductive iterative revision Classification: Education

Methodologies: Mixed

Area of Interest: Education Administration 
$A^{s}$ s institutions of higher learning come under increasing scrutiny by the public, colleges and universities are pressured to maintain relevant and current curriculums (Achtemeier \& Simpson, 2005). To be sure, higher education institutions are compelled to engage in continuous improvement processes in order to obtain or maintain their accreditations. Mammoth curricular redesign calls for a systematic and strategic approach for successful implementation (Cleaver, Wills, Gormally, Grey, Johnson \& Rippingale, 2017).

One of the more daunting tasks relative to continuous improvement in academe is the process of curricular review. Faculty in all disciplines report feeling overwhelmed the process of overhauling their curricula. Although most faculty recognize its importance, Downey et al. (2019) note that there is often disagreement on how to structure and implement changes. Determining the most organized approach, while sifting through many bits of information makes the process unwieldy, massive, and overly complex. The process can also evoke strong opinions and emotions as difficult decisions are made about curriculum and courses. Consequently, conflicts can occur as faculty with differing priorities and visions work together to reach consensus (Downey et al., 2019).

This paper details a deductive, participative, and iterative framework for curricular revision. Most curricular redesign approaches are linear in nature, with researchers advocating a step-by-step process ( Laughlin \& Kean, 1995; Downey et al., 2019; Pederson \& Burns, 2011; Bennett \& Walston, 2015). In practice, such a neat and tidy approach is rarely followed or even possible. Inevitably, the process is messy and iterative in nature. In the current paper, a case example is provided from a curricular redesign at a public university in a Merchandising and Fashion Design program. A systematic, organized process is presented and specifies components used in curricular review. A discussion of curriculum as well as behavioral outcomes are discussed.

\section{Theoretical Framework}

The goal of education is to facilitate change and learning (Rodgers, 1969). Laughlin and Kean (1995) note that merchandising and fashion design programs are "scrambling" to update and maintain the current curriculum. Among the disrupting forces include "rapid changes in technology, values, shifting responsibilities, international migration, environmental activism, changing demographics, and stressed economies (p. 184)." The researchers advocate for academicians to constantly conduct environmental scanning as part of the institutional continuous improvement process. Indeed, their 1995 study was intended to provide baseline data for institutions to use in strategic planning of curricular review (Laughlin \& Kean, 1995). More recently, other researchers have presented their linear approach to curriculum integration and revision of - curricula (Pedersen \& Burns, 2011; Bennett \& Walston, 2015).

Garner and Buckley (1988) wisely stated that a strong curriculum should focus on three key constituents, namely, "the educators that provide the curriculum, students who experience the curriculum, and the employers who hire the graduates of these programs" (pg. 32). Researchers have long studied trends in curriculum changes in the area of Merchandising and Fashion Design (Laughlin \& Kean, 1995; Garner \& Buckley, 1988; Shim, 1984; Frazier \& Cheek, 2015). In 1995, the International Textile and Apparel Association endorsed a set of competencies for use in curricular review (Kunz, 1995). Subsequently revised in 2008 , the competencies were intended to be used as a guiding framework in curricular design and were termed "meta-goals" (ITAA, 2008). Many universities have used the general framework to institute curricular changes (Cheek, Davis, Frazier, Pasricha, and RuppertStroescu, 2012).

Frazier and Cheek (2015) built on the research regarding the ITAA competencies by examining perceptions of industry professionals. Their survey revealed that soft skills were perceived to be particularly important for entry-level retailers. Teamwork, leadership, self-awareness, critical thinking, and technological skills were also perceived as favorable attributes for recent college graduates in 
merchandising. The researchers note that the necessary knowledge, skills, and abilities in the field of merchandising and fashion design will continue to morph over time. Palomo-Lovinski, Copeland, and Kim (2019) note that fashion programs should, indeed, meet the immediate needs of the fashion industry.

The curricular review process is an institutional practice that is similar in many institutions of higher education. It is a vehicle by which curricular changes are adopted. Typically, changes are originated by faculty members and proposals flow through a sometimes arduous process (Miller and Harder, 2014). Indeed, the process is a ground up approach by which faculty have a vision of a curricular modification which involves significant preliminary work involving benchmarking and other data collection. Initial proposals start at the departmental level and are often vetted by a departmental curricular committee. Proposals are then submitted to a college level committee and then vetted through a university body (oftentimes a Faculty Senate). Final approval must be given by the Provost, the President of the university, and ultimately the board of trustees of the institution.

\section{The Context}

The university in this example is a public, comprehensive metropolitan system with a statewide mission in public affairs whose purpose is to develop educated persons. The University's identity is distinguished by its public affairs mission, which entails a campus-wide commitment to foster expertise and responsibility in ethical leadership, cultural competence and community engagement.

As of the Fall 2018 semester, the University enrolled 24,390 students and offered more than 190 bachelor degree options and over 100 graduate degrees. The College of Business, one of the largest business colleges in the Midwest region, includes four departments - Computer Information Systems (CIS), Finance and General Business (FGB), Management (MGT), and Marketing (MKT) - and the School of Accountancy (ACC) in the business unit, as well as two separately accredited departments Merchandising and Fashion Design (MFD) and Technology and Construction Management (TCM) - that are outside of the business unit.

\section{The Department}

The Department of Merchandising and Fashion Design provides education, scholarship, and service in the areas of human services and professional career education. Its vision centers on the study of merchandising and clothing as they relate to the physical, social, psychological, economic, aesthetic, and cultural perspectives of persons in the global community.

The department's mission statement is consistent with the University's Long Range Plan and Mission relating to its commitment to student learning, inclusive excellence and institutional impact as part of the Public Affairs Mission of the University. The department emphasizes experiential learning and, consistent with the University's mission, social responsibility.

The B.S in Fashion Merchandising and Design offers two possible emphases: that in Merchandising and Product Development, and in Fashion Design and Product Development. Both options require students to complete a set of core classes establishing a foundation in textiles, fashion history, merchandising math, and product development. Each of the core courses incorporates valuable information within the course content. Therefore, it was important to review the teaching strategies, techniques and course outcome of the core courses every three years. Through periodic review, both options in the department benefit from timely curricular review and impactful changes. Indeed, the fashion industry is ever-changing and for continued growth in the department it is important to remain current and innovative. The department's focus is immersing students in the industry-based curriculum that is based in experiential learning.

\section{The Process}


Most curricular revision frameworks suggested in the literature are linear in nature (e.g. Pedersen \& Burns, 2011; Bennett \& Walston, 2015). We propose an alternative model that reflects the iterative process inevitable in the practice of curricular redesign. The guiding framework for the current study is based on Garner and Buckley (1988). That is, feedback was solicited and incorporated from educators, students, and employers. The process that ensued was, indeed, deductive, participative, and iterative in nature. That is, in each two-year process, the program was viewed as a whole, with input from faculty at every step, and also viewed from a micro-perspective by examining each course individually. The deductive and iterative process ensured that faculty received the most relevant and comprehensive data possible. The department head served as a facilitator, organizer, and scribe for the meetings. The process included peer review, with each faculty member encouraged to review not only their own courses, but those of their colleagues as well. Our framework is modeled after an overarching continuous improvement process as recommended by Deming (2000) and required involvement from a multitude of stakeholders. The framework is illustrated in Figure 1.

Year 1

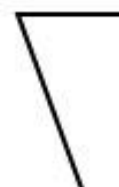

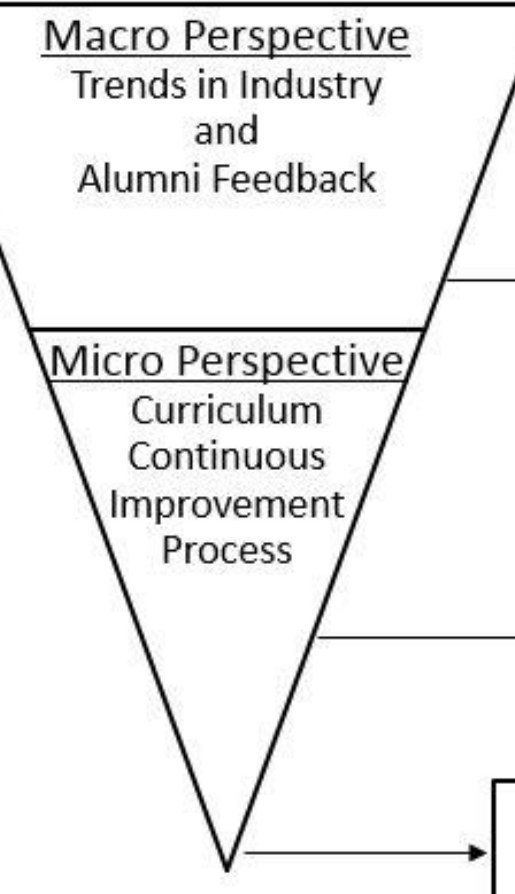

Figure 1. A Deductive, Participative, and Iterative Framework for Curricular Review

\section{Process in Year One Industry Review}

We concur with Laughlin and Kean (1995), that continual environmental scanning is imperative in determining trends and changes in the fashion industry. Plewa, Galan-Muros and Davey (2015) note industry collaboration in regard to curriculum design has received little attention in the literature despite its importance in enriching the educational process. Added benefits to seeking input from industry professionals is increased industry engagement, more active alumni networks, and heightened cooperation from industry partners (Plewa et. al, 2015). 
Hence, in Year 1, the department began the comprehensive curricular review by examining the industry as a whole. Research was conducted by gathering data from university websites and other database sources regarding curricula at other institutions. Additionally, faculty traveled to personally visit alumni in various cities across the United States. Alumni were interviewed regarding recent industry trends, technological changes, and new career opportunities in the merchandising and fashion industry. Valuable information regarding industry developments, current trends and techniques was obtained and later incorporated in curricular changes. Finally, a survey of students and alumni was conducted. Outside evaluation of the current program provided faculty with an additional perspective that was specific to the program. It was valuable to obtain both student and alumni/employer perspectives. Results from this survey can be found in Table 1.

A total of 103 participants were surveyed with fifty responses received resulting in a $49 \%$ response rate. Eighteen senior students and 32 alumni responded. Qualitative data was also collected from respondents. Common themes emerged. Respondents reported that they thought more technology should be incorporated into class structures and content. Students noted that they were willing to have additional material covered in courses if it would enable them to be more competitive in the job market. Logistics and supply chain courses and a textile lab were all noted as critical additions needed in a revised curriculum.

Table 1. Results of Student and Alumni/Employer Survey

\begin{tabular}{|l|l|}
\hline 1. Are you a current senior or graduate of the MFD program? & $100 \%$ \\
\hline 2. Which of the following courses have you completed or currently enrolled? & \\
\hline History of Costume & $92 \%$ \\
\hline Product Development & $98 \%$ \\
\hline Advanced Product Development & $90 \%$ \\
\hline Product Quality & $86 \%$ \\
\hline Post Internship & $96 \%$ \\
\hline All other classes & $100 \%$ \\
\hline
\end{tabular}




\begin{tabular}{|c|c|}
\hline 3. Which top 3 classes would you choose to be taught online? & \\
\hline History of Costume & $78 \%$ \\
\hline Textiles & $65 \%$ \\
\hline Introduction to Fashion & $75 \%$ \\
\hline $\begin{array}{l}\text { 4. Which classes do you feel need improvement or updated whether they are } \\
\text { offered online or in a seated class? }\end{array}$ & \\
\hline Textiles & $39.1 \%$ \\
\hline History of Costume & $39.1 \%$ \\
\hline Product Development & $54.4 \%$ \\
\hline $\begin{array}{l}\text { 5. Please share your honest opinion about issues you feel need to be } \\
\text { addressed in our course content or curriculum. (example: restructured, what } \\
\text { do you feel needs to be added to the course content, etc.?) }\end{array}$ & Varied \\
\hline Current Student Response & 18 \\
\hline Alumni & 32 \\
\hline Total & 50 \\
\hline
\end{tabular}




\section{Continuous Improvement Process}

In Fall 2017, the Department engaged in a curriculum continuous improvement process (CIP) for the department. It is anticipated that the department will engage in this process every 3 years. The $\mathrm{CIP}$ involved each faculty member completing the questions below. After completion, the department reviewed and discussed the data, and compiled the evidence collected by the team. The survey questions appear below:

1. Identify current and/or emerging issues that impact the content of this course and describe how these issues have been incorporated into the course. Provide evidence to substantiate the integration of the new information into the course.

2. Discuss how this course has been improved or updated in the current year.

3. Provide specific examples as to how faculty who teach this course are remaining current in their field (e.g., professional development seminars, personal readings, conference participation, etc., undertaken in the current academic year).

4. Identify any innovative and/or exemplary practices, innovations, activities, etc. related to the instruction and/or delivery of this course.

5. Are there some new directions you would like to take your course in? What specific issues are holding you back?

6. $\quad$ Provide a list of the standard topics covered in this course.

The data gathered in this step was used as a supplement to the Year 2 examination of specific courses.

\section{Process in Year Two Benchmarking}

Determining the best process for assessing academic depth and rigor in merchandising and fashion design education can be difficult. One starting point is to examine curricula from other institutions. To be sure, benchmarking in higher education cannot always be a strict comparison of courses from institution to institution. Rather, contextual variables must be taken into account (Steyn, van der Walt, and Wolhuter, 2016). Hence, the choice of benchmarking institutions were carefully selected in this exercise. An important step in creating a sound benchmarking system is to learn lessons from the content and content-structure of other programs (Steyn et al, 2016). Indeed, benchmarking is a useful tool that has been used by educational institutions and entities in the continuous improvement process (Weeks, 2000; McClenney, 2006; Muijtjens, Schuwirth, Cohen-Schotanus, Thoben \& vander Vleuten, 2008; Bosso, Chisholm-Burns, Nappi, Gubbins, \& Ross, 2010; Placek, Ochrana \& Pucek, 2015). The process of institution selection in using benchmarked data is essential as lessons, both positive and negative, can be learned and the results useful once comparisons are made (Furco \& Miller, 2009). Best practices can be identified and are critical in curricular review. By considering the context (e.g. size, nature, and structure of the institution, etc), institutions can be included in the analysis so that meaningful comparisons can be made.

In the current study, peer institutions were selected if they were public entities with a merchandising and fashion program and similar in size, university budgets, and program rankings. The choice of institutions was primarily based on similarity in both faculty and monetary resources. However, both smaller, larger, public and private institutions were also included in benchmarking data. It was important when developing a new curriculum for the department that benchmark programs were 
reviewed, however, the goal of the review was not to mimic benchmark institutions, but, rather, to also determine areas where the Department differentiated itself from other programs.

Using peer, competitive, and aspirant institutions as benchmarks, an analysis was conducted on the required courses for merchandising and fashion design programs. For each institution, a web search was conducted to determine the program name, which college the program was housed in, and the number of hours required for the program. A detailed analysis was performed on the required courses to determine similarities and differences among the programs. A comparison was also made with the current institution's core courses with that of the benchmark institutions. Posted course descriptions were reviewed and recorded if the course was required or an elective. After analyzing the information, a summary was prepared that included similarities, differences, and recommendations. Similar to the alumni interviews and survey results, it was found that a logistics course was a program gap.

\section{Program and Course Review}

At the start of the Fall 2018 semester, the MFD faculty engaged in a close examination of the current curriculum in the department. Osborne and Purkey (1995) note that "faculty peer review is essential to evaluate those aspects of personal and professional functioning that only faculty are uniquely qualified to judge" (p. 654). The MFD faculty identified norms and expectations at the start of the peer review process. Agreed upon norms included everyone's voice should be heard, no interruptions when someone is speaking, and honesty in thoughts and ideas will be respected. The process encouraged faculty to focus on the following overarching goals: students?

Are we providing the most up-to-date curriculum to our students? What is best for our We asked faculty to verbally respond to the following questions:

1. What differentiates us from other programs?

2. Are we teaching the most current techniques in the industry?

3. How are we providing the most current information in the classroom?

4. How are each of you staying up-to-date with your teaching materials?

We obtained further insight through a lively discussion and by, again, examining the program as a whole as well as by individual courses.

Next, the department decided on three questions that they would ask of each course in the curriculum:

1. Describe the current projects you are assigning in your classes. How current are the assignments?

2. Which text/teaching materials are you using? How current are your materials?

3. When was the last time you updated your course? What significant changes did you make? The faculty spent several hours discussing the methodology used in each course, as well as content, pedagogy, and assignments in all courses in the curriculum. Faculty reviewed the information gained from these discussions and compared it to the benchmarking data previously analyzed.

\section{Discussion and Outcomes of the Process}

At times, the curricular review process seemed overwhelming with the significant amount of data and resource constraints to consider. The systematic process presented above assisted in managing multiple considerations and constituents involved in the curriculum review. Benchmarking data was used in initial discussions and helpful in establishing institutional norms in curriculum. Also advantageous was to examine views of current students and alumni in order to provide varying perspectives and insights. 


\section{Behavioral Outcomes}

There were undoubtedly difficult conversations that ensued during the curricular discussions in the current study. There are many reasons why faculty may not be enthusiastic about curricular redesign. Palomo-Lovinski (2019) note that faculty often perceive roadblocks that can impede progress on needed curricular changes. Further, researchers note that there is often a lack of consensus on methodology and implementation of redesign efforts (Palomo-Lovinski et al., 2019).

In essence, there exists resistance to change and power issues that often plague the curricular revision process (Downey et al., 2019). Senior faculty will no doubt weigh the costs associated with making curricular changes. That is, they must decide if making course and programmatic changes is worth the effort when retirement is on the horizon. Senior faculty are often comfortable with their course preparations and can be reluctant to make significant changes (Bland \& Berquist, 1997; Huston, Norman \& Ambrose, 2007). On the other hand, the tenure and promotion process confines junior faculty. They may perceive that their time is better spent on teaching and research endeavors (PalomoLovinski, et al., 2019).

Power issues can also plague the process. The academic environment can be political and the balance of power between junior and senior faculty skewed. While junior faculty may be more open to change, they are often keenly aware of the balance of power issues within their work group. Hence, potential resistance to change and the power imbalance between faculty can sway the curricular revision process in a potentially unproductive way. However, as Downey et al. (2019) note, motivation may be piqued if all faculty are frustrated with the existing curriculum.

Indeed, difficult issues arose out of the curricular discussions in the current study. Indicative of a healthy team environment, disagreements were inherent in the conversations. The spirit of inclusiveness was an important norm to establish. These difficulties served an important purpose. It was apparent that underlying issues existed within the department. Resistance to change and power issues emerged. The many curriculum meetings over the two-year period served to address deeply held perceptions and issues plaguing the department for many years. It was an opportunity to address and discuss strongly held views on curriculum and the process of changing courses within the department. Although some discussions were, indeed difficult, it was important that all voices were heard. The wisdom of Laughlin and Kean (1995) of developing a "broad based, yet focused, and strong foundation in textile and clothing" (pg. 196), guided discussions as well.

\section{Curricular Outcomes}

At several points throughout the process, individual faculty members, and, at times, the faculty as a whole realized that there were needed changes in the curriculum. An "outsider's" perspective was provided by the merchandising faculty on the design curriculum, and the design faculty, in turn, weighed in on merchandising courses. Although these conversations proved to be challenging at times, the discussions provided insights from another perspective.

Palomo-Lovinski et al. (2019) note that the fashion industry desires graduates well-versed in the knowledge of the supply and value chain including "sourcing, product development, production, manufacturing, distribution, retail and marketing" (p. 364). An examination of the benchmarking data in the current study revealed an important gap in the curriculum. It was noted that most fashion programs included a supply chain/logistics course as a required class in their program. A decision was made to include such a course as a core class in the curriculum.

Consistent with the experiential learning emphasis in the College of Business, the merchandising and design faculty instituted a major change in the senior capstone class. Resulting from the curriculum discussions, the course is now a real-world simulation experience for students. The senior fashion 
students construct a three to five-piece apparel collection ranging from children's wear, bridal, ready to wear to men's apparel. In April of each year, a jury of three industry experts review the student collections and select one garment from each collection that is showcased during the runway show at a Senior Market event. The market environment allows the design students to share their vision for their collections, while guests can touch and examine garments of the designers. Merchandising students assist each designer in both presenting and positioning the collection. Hence, the capstone event highlights both the work of design and merchandising students. A poster board session showcases all the works of merchandising students from the freshman through senior level classes. The first annual Senior Market was attended by over 500 parents, friends, community members, local businesses, local designers, potential employers and prospective students. The event provides merchandising and design students with a glimpse of real-world experience.

While examining the curriculum, conversations ensued concerning accreditation and assessment of learning outcomes. The department realized that they should establish stronger assessment processes that more closely align with existing accreditation and industry standards within the program. The following academic year will focus on the assessment of learning processes in the department.

The undertaking also highlighted the necessity that faculty would need to develop, re-sequence, and re-staff courses. During the process, we discovered that new technology needs including machinery and software were necessary to maintain curriculum relevance. The department discussed staffing needs at length given the major changes in scheduling and course content.

\section{Recommendations}

The contribution of this study lies not in the specific data results presented, but rather, the methodical and comprehensive approach to curricular redesign offered here. Ongoing curricular review is important to maintaining relevant and current curricula. The process is messy and often unwieldy. The process is also inherently iterative and non-linear, consistent with the spirit of continuous improvement. Departments must view programs and curriculum from both a macro-perspective as well as a micro view as both are important in the process. A successful curriculum review must be participative as faculty work together to develop courses and programs that are relevant and current. Through this deductive, iterative, and participative process, faulty establish and maintain strong curricula. In the current study, faculty reported that departmental goals were met related to the curricular review. Although there was more buy-in from some faculty compared to others, overall, all faculty agreed that the changes made the program stronger.

Based on the framework provided in this paper, we offer a number of recommendations as faculty engage in curricular revision. First, we suggest that formulating a plan for the process before curricular discussions begin will enable easier management of meetings and discussions. In this paper we offer a framework to be utilized for significant curricular redesign. Our approach, unlike other models currently offered, more closely mirrors practice rather than theory. Our framework recognizes the iterative nature of curricular revision rather than the linearity of other models that have been presented in the literature. Second, we strongly urge those facilitating the process to understand the underlying motivations of the faculty involved. Such understanding can enable leaders to better navigate difficult conversations. Recognizing motivations can explain resistance and power issues which can plague the process. Third, the process should be participative in nature as our framework and others' advocate (Pedersen \& Burns, 2011). Widespread participation can help facilitators build support for curricular changes. Fourth, consensus in curricular decisions should be the goal. The participative 
nature of the framework presented can help faculty achieve consensus in the unwieldy process. Fifth, as our framework advocates, external perspectives from industry professionals and alumni can provide much needed input when difficult decisions are made. Sixth, all parties should agree on a realistic timetable. The framework presented here suggests a two year duration, however, resources and time availability ultimately determine the appropriate timetable. Finally, student success should be the cornerstone of curricular revision. The goal for all parties involved should be to prepare students for successful careers in their industry of choosing. Student success is the ultimate external validation of a curriculum (Downey et al., 2019).

\section{Conclusion}

Besides maintaining a relevant and current curriculum, the process as outlined above provided a multitude of benefits for this department. The department made significant changes to the curriculum, and re-established more honest relationships and increased understanding among colleagues, which was an unexpected benefit of the lengthy process. The ultimate goal, however, was to develop critical thinking and current technological skills for students.

Future studies of curricular redesign could quantify constituent satisfaction with utilizing the proposed framework. The effectiveness with institutionalizing curricular changes is another research avenue subsequent to curricular review. An assessment of changes made is an important part of the process. Future research could explore the assessment of learning after a curriculum review is conducted. 


\section{References}

Balfanz, R., \& Byrnes, V. (2012). The Importance of Being in School: A Report on Absenteeism in the Nation's Public Schools. Baltimore, MD: Johns Hopkins University Center for Social Organization of Schools. Retrieved from http://new.every1graduates.org/wpcontent/uploads/2012/05/FINALChronicAbsenteeismReport_May16.pdf

Blankstein, A. M., Noguera, P., Kelly, L., \& Tutu, D. (2015). Excellence through equity: Five principles of courageous leadership to guide achievement for every student. Thousand Oaks, CA: Corwin.

Boyd, J. (2008). Coaching in context. State of Victoria, Australia: Department of Education.

Cooper, C. W. (2009). Performing cultural work in demographically changing schools: Implications for expanding transformative leadership frameworks. Educational Administration Quarterly, 45(5), 694-724.

Costa, J. (2015). Preparing school leaders to advocate for social justice: A case analysis of social justice tenets in a leadership preparation program (WIDA Research Brief). Retrieved from www.wida.us/downloadLibrary.aspx

Every Student Succeeds Act (2015). U. S. Department of Education. Retrieved from https://www.gpo.gov/fdsys/pkg/BILLS-114s1177enr/pdf/BILLS-114s1177enr.pdf

Freire, P. (1998). Pedagogy of freedom: Ethics, democracy, and civic courage. New York, NY: Rowman \& Littlefield Publishers, Inc.

Garmston, R. J., \& Wellman, B. M. (1999). The adaptive school: A sourcebook for developing collaborative groups. Norwood, MA: Christopher-Gordon Publishers.

Gray, M. (2011). Back to basics: A critique of the strengths perspective in social work. Families in Society: The Journal of Contemporary Social Services, 92(1), 5-11. DOI: 10.1606/1044-3894.4054.

Guskey, T. R. (2002). Does it make a difference? Evaluating professional development. Educational Leadership, 59(6), 45-51.

Jensen, E. (2009). Teaching with poverty in mind: What being poor does to kids' brains and what schools can do about it. Alexandria, VA: ASCD.

Leadership Conference on Human Rights. (2016, August 1). Statement of 31 Civil and Human Rights and Education Groups on Draft ESSA Accountability Regulations. Retrieved from http://www.civilrights.org/press/2016/essa-accountability-regs.html

Morgan, E., Salomon, N., Plotkin, M., \& Cohen, R. (2014). The School Discipline Consensus Report: Strategies from the Field to Keep Students Engaged in School and Out of the Juvenile Justice System. New York, NY: Council of State Governments Justice Center. Retrieved from http://csgjusticecenter.org/youth/school-discipline-consensus-report/

National Policy Board for Educational Administration. (2015). Professional Standards for Educational Leaders. Reston, VA: Author.

Neufeld, B., \& Roper, D. (2003). Coaching: A strategy for developing instructional capacity. Providence, RI: Education Matters and Annenberg Institute for School Reform.

Osta, K., \& Perrow, M. (2008). Coaching for educational equity: The BayCES coaching Framework. San Francisco, CA: Bay Area Coalition for Equitable Schools. 
Ryan, J. (2006). Inclusive Leadership. San Francisco, CA: Jossey-Bass.

Saleh, A., McBride, J., \& Henley, J. (2006). Aspiring school leaders reflect on the internship. Academic Exchange Quarterly, 10(3).

Senge, P. M. (1994). The fifth discipline fieldbook: Strategies and tools for building a learning organization. New York, NY: Doubleday.

Shields, C. (2013). Transformative leadership in education: Equitable change in an uncertain and complex world. New York: Routledge.

Starratt, R. J. (1991), Building an ethical school: A theory for practice in educational leadership. Educational Administration Quarterly, 27(2),155-202.

The Aspen Education \& Society Program and the Council of Chief State School Officers. (2016). Advancing Equity through ESSA: Strategies for State Leaders. Retrieved from https://www.aspeninstitute.org/publications/advancing-equity-essa-strategies-state-leaders/

U. S. Commission on Civil Rights. (2018, January 10). Public education funding inequity in an era of increasing concentration of poverty and resegregation. Washington, D.C.: Briefing before the United States Commission on Civil Rights. Retrieved from http://www.usccr.gov/pubs/2018-0110-Education-Inequity.pdf

Valdez, T., \& Lugg, C. (2010). Community cultural wealth and Chicano/Latino students. Journal of School Public Relations, 31(3).

Yosso, T. J. (2005). Whose culture has capital? A critical race theory discussion of community cultural wealth. Race Ethnicity and Education, 8(1), 69-91. 


\section{About the Authors}

Dr. Elizabeth Rozell (erozell@missouristate.edu) received her Ph.D. in Business Administration (Management) from the University of Mississippi. She is Associate Dean and Professor of Management at Missouri State University and has taught for over 25 years. She has authored over 60 publications which have appeared in such journals as Personnel Psychology, Group and Organization Studies, and the Journal of Psychology. She has conducted numerous consulting projects in both the private and public sectors. Dr. Rozell is the Kenneth E. Meyer Professor of Management which was awarded by the College of Business on the basis of her laudable performance in research.

Dr. Jenifer Roberts received her Ph.D. in Business Administration (Marketing) from Northcentral University in Arizona. She is an Associate Professor in the Merchandising and Fashion Design Department and has taught for over 25 years. She brings to the classroom over 20 years of industry experience in Buying, Product Development, Professional Development, and Entrepreneurship. She has many merchandising presentations and published proceedings from ITAA. Her publications have appeared in Journal of Textile Engineering \& Fashion Technology and Human-Computer Interaction where she and her co-authors received the best paper award at the Human-Computer Interaction Conference.

Dr. Cathy Starr received her Ph.D. in Human Environmental Sciences from Oklahoma State University. She is an Associate Professor in the Merchandising and Fashion Design Department and has taught for over 20 years. Her publications have appeared in Human-Computer Interaction, Clothing and Textile Research Journal, International Journal of Consumer Studies, Journal of Textile Apparel Technology and Management, and the Journal of Korean Society for the Clothing Industry. Awards include Best Solution to a Design Problem Award at the International Textile and Apparel Association, COB Summer Research Fellowship, and NASA Oklahoma Space Grant Consortium Fellowship.

Ms. Sandy Bailey received her Masters of Science in Management from Baker University. She is an Assistant Professor of Merchandising and Fashion Design and has taught design classes for over 20 years. She brings to the classroom over 20 years of corporate industry experience in Technical Design, Flat Pattern, and Computer Apparel Applications (Gerber and Kaledo). She has many merchandising presentations and published proceedings from ITAA. Her publications have appeared in Fashion Technology and Human-Computer Interaction where she and her co-authors received the best paper award at the Human-Computer Interaction Conference. 